\title{
PENGARUH SELF EFFICACY DAN LOCUS OF CONTROL TERHADAP KINERJA KARYAWAN (Studi Pada Ramayana Mal Bali)
}

\author{
Iwan Restu Ary ${ }^{1}$ \\ Anak Agung Ayu Sriathi ${ }^{2}$ \\ ${ }^{1,2}$ Fakultas Ekonomi dan Bisnis Universitas Udayana, Bali, Indonesia \\ e-mail: restuiwan1@gmail.com
}

\begin{abstract}
ABSTRAK
Kinerja menjadi landasan yang sesungguhnya bagi organisasi karena tanpa adanya kinerja maka tujuan yang dimiliki oleh organisasi tidak dapat dicapai. Penelitian ini bertujuan untuk menjelaskan pengaruh self efficacy dan locus of control terhadap kinerja karyawan studi pada Ramayana Mal Bali. Penelitian ini dilakukan pada perusahaan Ramayana Mal Bali. Jumlah sampel yang digunakan sebanyak 64 orang karyawan, dengan metode simple random sampling. Data dari penelitian ini adalah data primer yang diperoleh dari hasil observasi, wawancara dan penyebaran kuesioner. Teknik analisis yang digunakan adalah regresi linier berganda. Berdasarkan hasil analisis yang telah dilakukan dapat disimpulkan bahwa self efficacy berpengaruh positif dan signifikan terhadap kinerja karyawan. Locus of control berpengaruh positif dan signifikan terhadap kinerja karyawan. Self efficacy dan locus of control secara bersama-sama berpengaruh terhadap kinerja karyawan.
\end{abstract}

Kata kunci: kinerja karyawan, self efficacy, locus of control

\begin{abstract}
Performance becomes the real foundation for the organization because without the performance of the objectives owned by the organization can not be achieved. This study aims to describe the influence of self efficacy and locus of control to employee performance study on Ramayana Mal Bali. This research was conducted at Ramayana Mal Bali Company. The number of samples used are 64 employees, with simple random sampling method. Data from this research are primary data obtained from observation, interview and questionnaire distribution. The analysis technique used is multiple linear regression. Based on the results of the analysis that has been done can be concluded that self efficacy has a positive and significant effect on employee performance. Locus of control has a positive and significant effect on employee performance. Self efficacy and locus of control together affect the employee performance.
\end{abstract}

Keywords: employee performance, self efficacy, locus of control

\section{PENDAHULUAN}


Persaingan antara perusahaan menjadi lebih sengit dan kompetitif pada era globalisasi saat ini. Adanya persaingan tersebut, mengharuskan perusahaan untuk terus memperhatikan kebutuhan dan keinginan konsumen serta mewujudkannya dengan cara dan hasil yang lebih baik dari yang dilakukan oleh pesaingnya. Diharapkan dengan kinerja perusahaan yang baik dalam memenuhi kebutuhan serta keinginan tersebut, konsumen bisa merasa puas dan melakukan pembelian yang berulang pada perusahaan tersebut. Karena organisasi merupakan lembaga yang digerakkan oleh manusia maka kesesuaian perilaku karyawan dengan standar kerja yang sesuai akan menghasilkan kinerja yang memenuhi harapan.

Kinerja menjadi landasan yang sesungguhnya bagi organisasi karena tanpa adanya kinerja maka tujuan yang dimiliki oleh organisasi tidak dapat dicapai. Karyawan yang memiliki kinerja yang baik akan mampu menyelesaikan permasalah dan tugas-tugas yang dibebankan oleh organisasi. Kinerja menjadi gambaran mengenai tingkat pencapaian pelaksanaan suatu kegiatan dalam mewujudkan sasaran, tujuan, visi dan misi organisasi yang tertuang dalam strategi perencanaan suatu organisasi. Karenanya kinerja karyawan merupakan hal yang patut mendapat perhatian penting dari pihak perusahaan. Kinerja dari sumber daya manusia yang baik, mampu berkontribusi untuk kinerja dan kemajuan perusahaan tersebut. Kinerja adalah tindakan nyata yang ditunjukan oleh individu dalam bentuk prestasi yang tercipta dari hasil kerjanya dalam posisi atau jabatan tertentu pada suatu perusahaan tempat ia bekerja (Al Azhar, 2013). Terdapat faktor-faktor yang dapat mempengaruhi kinerja karyawan yaitu, faktor internal karyawan, 
Iwan Restu Ary, Pengaruh Self Efficacy dan Locus of Control ...

faktor lingkungan internal oranisasi dan faktor lingkungan eksternal organisasi (Wirawan, 2009: 6).

Self efficacy merupakan salah satu aspek pengetahuan tentang diri atau selfknowledge yang memberikan pengaruh pada kehidupan sehari-hari manusia. Self efficacy merupakan keyakinan yang dimiliki oleh individu dalam menyelesaikan tugas atau masalah yang dihadapi dalam pekerjaannya (Lunnenburg, 2011). Self efficacy juga berpengaruh bagi individu dalam bertindak dan membuat keputusan untuk mencapai tujuannya. Motivasi diri yang timbul dalam diri seseorang didorong oleh rasa percaya akan kemampuan yang dimiliki daripada sesuatu yang benar secara objektif (Medhayanti, 2015).

Engko (2008) menyatakan bahwa self efficacy mampu mempengaruhi kinerja dari seorang karyawan. Self efficacy juga berpengaruh signifikan pada kinerja, hal tersebut juga dikemukakan pada penelitian Arshanti (2009) dan Fadzilah (2006). Self efficacy dapat mempengaruhi cara pandang seseorang dalam berpikir, merasakan, berkelakuan dan memotivasi dirinya sendiri (Handayani, 2008). Rimper dan Lotje (2014) secara jelas menyatakan bahwa ada pengaruh yang diberikan oleh variabel self efficacy terhadap kinerja. Persepsi pribadi seperti ini sangat berperan dalam mengembangkan niat individu. Self efficacy yang tinggi dalam diri seseorang mampu memberikan kemampuan untuk bertahan dalam kesulitan yang dihadapi serta mampu mengatasi persoalan atau hambatan yang mengganggu dalam mencapai tujuannya (Cherian dan Jolly, 2013). Namun terdapat Research gap penelitian dari Kaseger (2013) menemukan bahwa variabel self efficacy tidak berpengaruh secara positif dan signifikan terhadap kinerja. 
Locus of control adalah sifat kepribadian yang menjelaskan persepsi dari mana individu menentukan penyebab peristiwa-peristiwa dalam hidup (Malik et al., 2015). Dewi (2014) menyatakan locus of control adalah sifat kepribadian seseorang dalam menginterpretasikan kesuksesan dan kegagalan yang dialami berasal dari faktor internal diri atau faktor eksternal. Locus of control diartikan sebagai keyakinan seseorang tentang bagaimana dan dimana peristiwa dirasakan menyenangkan atau tidak menyenangkan, menjadi dasar untuk bertindak (Elena et al., 2015). Locus of control merupakan cara pandang seseorang dalam menanggapi suatu kejadian yang datang dalam kehidupannya. Menurut Widyaninggrat (2014) locus of control menunjukan seberapa besar keyakinan seseorang mengenai hubungan antara perbuatan yang dilakukan dengan hasil yang diterima. Locus of control berkaitan dengan sikap kerja seseorang dan citra diri yang dimilikinya. Robbins dan Judge (2008:138), membagi locus of control menjadi dua, yaitu: locus of control internal dan eksternal. Modise dan Patient (2017) mereka yang cenderung memiliki locus of control eksternal akan merasa setiap kejadian yang dialami dalam hidupnya berada diluar kendalinya misalkan karena kebetulan, nasib atau sebuah keberuntungan dan untuk orang dengan locus of control internal yang dominan akan merasa memiliki peranan atau kekuatan dalam setiap hal yang terjadi dalam hidupnya.

Studi yang dilakukan oleh Wahyuni dkk. (2016) menyatakan bahwa internal locus of control yang semakin tinggi dapat mendorong peningkatan kinerja karyawan. Selain itu pada penelitian Dl. Wuryaningsih dan Kuswanti (2013), Gurendrawati et al. (2014), Appiah dan Addai (2014) menyatakan bahwa locus of 
Iwan Restu Ary, Pengaruh Self Efficacy dan Locus of Control ...

control dapat mempengaruhi kinerja dari karyawan. Kegagalan dalam suatu pekerjaan sebaiknya ditanggapi sebagai hal yang labil, dimana kita beranggapan bahwa keberhasilan yang dicapai merupakan akibat oleh faktor eksternal dan ketika mengalami kegagalan faktor internal dikatakan sebagai penyebabnya (Yi Li et al., 2014). Menurut Ayudiati (2010) kemampuan dalam menempatkan faktor internal dan eksternal yang tepat dalam menghadapi suatu kejadian mampu memberikan dampak yang baik bagi seseorang. Locus of control memiliki keyakinan yang mendalam dan beranggapan saat seseorang melakukan hal positif maka hasil yang akan diterimanya juga positif dan begitu juga sebaliknya saat orang beranggapan negatif dalam melakukan suatu pekerjaan maka hasil negatif juga yang akan didapatkannya (Ridhawati dan Ibnu, 2014). Serta pada penelitian Al Azhar (2013) juga menyatakan bahwa variabel locus of control tidak berpengaruh secara positif dan signifikan terhadap kinerja.

Seperti yang kita ketahui Ramayana Mal Bali merupakan perusahan yang menyediakan berbagai kebutuhan untuk individu khususnya pakaian serta beberapa jenis kebutuhan pokok seperti bahan makanan peralatana rumah tangga dan lainnya. Berdasarkan hasil wawancara yang dilakukan dengan ibu Ayu Manajer Human Resourse Development Ramaya Mal Bali untuk periode 20142015, didapatkan informasi yang menyatakan bahwa terdapat 4 kali pengaduan konsumen terhadap pelayanan yang diberikan oleh pramuniaga dan dua pengaduan terhadap kualitas barang yang ditawarkan. Selain itu kurangnya kemampuan dan kemandirian dari para pramuniaga dalam menyelesaikan setiap tugas yang dibebankan. Untuk penjualan yang dilakukan dari pihak Ramayana 
Mal Bali, memang mengalami kenaikan sebesar tiga persen dari periode sebelumnya namun di sertiap target bulanan yang diberikan sebagian besar pramuniaga belum bisa mencapainya.

Berdasarkan latar belakang tersebut, maka rumusan masalah penelitian ini adalah 1) Bagaimana pengaruh self efficacy terhadap kinerja karyawan pada Ramayana Mal Bali? ; 2) Bagaimana pengaruh locus of control terhadap kinerja karyawan pada Ramayana Mal Bali?

Tujuan dari penelitian ini antara lain 1) Untuk menguji pengaruh self efficacy terhadap kinerja karyawan pada Ramayana Mal Bali ; 2) Untuk menguji pengaruh locus of control terhadap kinerja karyawan pada Ramayana Mal Bali. Manfaat penelitian ini ada dua, pertama manfaat teoretis, hasil penelitian ini diharapkan dapat memberikan manfaat kelengkapan teoritis mahasiswa pada bidang manajemen sumber daya manusia. Khususnya pada bidang self efficacy, locus of control dan kinerja karyawan. Manfaat praktis, hasil dari penelitian ini sebagai bahan pertimbangan, informasi dan sumbangan pemikiran bagi perusahaan di bidang self efficacy, locus of control dan kinerja karyawan.

Kinerja adalah tindakan nyata yang di tunjukan oleh individu dalam bentuk prestasi yang tercipta dari hasil kerjanya dalam posisi atau jabatan tertentu pada suatu perusahaan (Al Azhar, 2013). Faktor-faktor yang mempengaruhi kinerja karyawan (Wirawan, 2009: 7), yaitu: 1) Faktor internal karyawan ; 2) Faktor lingkungan internal organisasi ; 3) Faktor lingkungan eksternal organisasi.

Kriteria kinerja adalah dimensi dimana kinerja perseorangan, tim, atau unit kerja diberi penilaian. Kriteria kinerja harus mencakup kinerja pekerjaan dengan 
tugas yang spesifik dan sebagai anggota perusahaan (Jackson dkk., 2011:76). Phopal (2012:205) menyatakan terdapat empat indikator dalam standar kinerja pada suatu perusahaan, yaitu standar kualitas, standar kuantitas standar waktu, standar efisiensi biaya.

Self efficacy merupakan bagian dari pengetahuan mengenai diri sendiri yang mampu memberikan pengaruh pada kehidupan sehari-hari manusia. Self efficacy dapat dikatakan sebagai faktor personal yang membedakan setiap individu dan perubahan self efficacy dapat menyebabkan terjadinya perubahan perilaku terutama dalam penyelesaian tugas dan tujuan (Trilolita dkk., 2017). Dimensi yang memiliki implikasi terhadap performa individu (Pinasti, 2011), yaitu: 1) Level magnitude merupakan derajat kesulitan tugas dimana individu merasa mampu atau tidak untuk melakukannya, sebab kemampuan diri yang dimiliki masing-masing individu berbeda-beda. 2) Strength merupakan tingkat kekuatan dari keyakinan atau pengharapan individu mengenai kemampuannya. 3) Generality merupakan keyakinan individu akan kemampuannya melaksanakan tugasnya di berbagai aktivitas yang dikerjakannya.

Locus of control merupakan kepercayaan individu dalam mengontrol kejadian yang mempengaruhi dirinya (Basak dan Ghosh, 2011). Rahayuningsih (2016) menyatakan beberapa dimensi locus of control internal dan eksternal, yaitu: suka bekerja keras, memiliki inisiatif yang tinggi, selalu berusaha untuk menemukan pemecahan masalah, selalu mencoba untuk berfikir seefektif mungkin, selalu mempunyai persepsi bahwa usaha harus dilakukan jika ingin berhasil, mudah menyerah, kurang suka berusaha karena mereka percaya bahwa 
faktor luarlah yang mengontrol, kurang mencari informasi, mempunyai harapan bahwa ada sedikit korelasi antara usaha dan kesuksesan, lebih mudah dipengaruhi dan tergantung pada petunjuk orang lain.

\section{Gambar 1. Kerangka Konseptual}

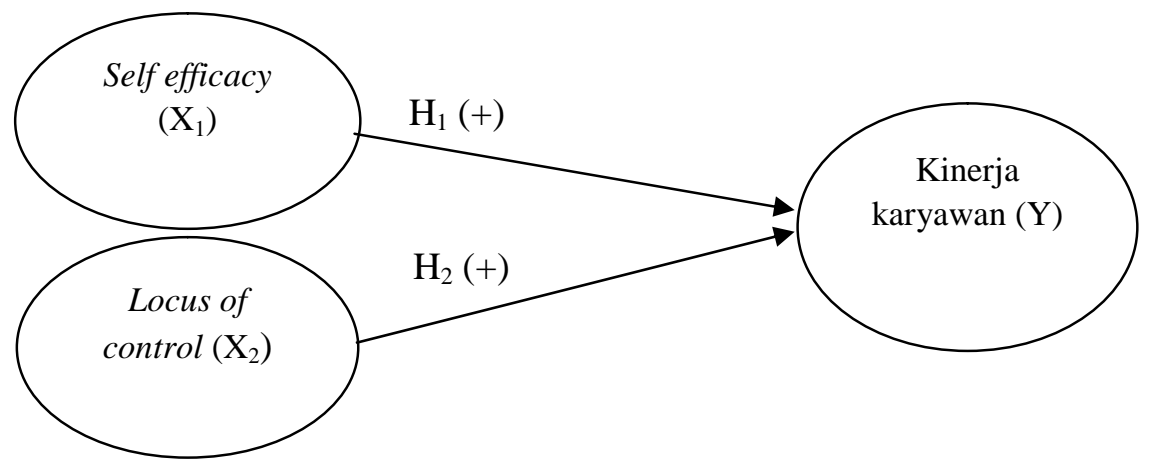

Sumber: $\mathrm{H}_{1}$ : Kilapong (2013); Indrawati (2014); Cherian dan Jolly (2013); Rimper dan Lotje (2014); Lunnenburg (2011). $\mathrm{H}_{2}$ : Wahyuni dkk. (2016); Wuryaningsih dan Rini Kuswanti (2013); Gurendrawati et al. (2014); Appiah dan Addai (2014); Rahayuningsih (2016).

Kilapong (2013) menyatakan self efficacy yang tinggi akan membuat karyawan lebih optimis dalam menyelesaikan pekerjaan yang di bebankan namum begitu juga sebaliknya apabila karyawan memiliki self efficacy yangrendahmaka karyawan tersebut akan merasa kurang percaya diri dalam menyelesaikan pekerjaannya. Self efficacy dapat dikatakan sebagai faktor personal yang membedakan setiap individu, dimana perubahan self efficacy dapat menyebabkan perubahan perilaku terutama dalam penyelesaian tugas dan tujuan (Indrawati, 2014). Penelitian Cherian dan Jolly (2013) menyatakan bahwa self efficacy secara positif berpengaruh terhadap kinerja yang dimiliki oleh karyawan, hal yang serupa juga dinyatakan dalam penelitian Rimper dan Lotje (2014). Lunnenburg (2011) menyatakan bahwa karyawan dengan self efficacy yang tinggi akan mampu 
Iwan Restu Ary, Pengaruh Self Efficacy dan Locus of Control ...

meningkatkan prestasi kerja dari karyawan itu sendiri. Berdasarkan uraian tersebut maka hipotesis yang digunakan sebagai berikut.

$\mathrm{H}_{1} \quad$ : Self Efficacy berpengaruh positif dan signifikan terhadap Kinerja Karyawa

Wahyuni dkk. (2016) menyatakan bahwa semakin tingi internal locus of control yang dimiliki dapat mendorong peningkatan kinerja karyawan. Penelitian Wuryaningsih dan Kuswanti (2013) menyatakan kinerja individu akan semakin baik dengan adanya locus of control pada karyawan. Locus of control memainkan peranan yang penting dalam meningkatkan kinerja (Gurendrawati et al., 2014), Appiah dan Addai (2014) menyatakan karyawan dengan internal locus of control yang tinggi akan memiliki peringkat kinerja kontekstual lebih tinggi dibandingkan karyawan dengan tingkat internal locus of control lebih rendah. Rahayuningsih (2016) menyatakan bahwa semakin kuat locus of control maka semakin kuat juga kinerja dari karyawan tersebut.

$\mathrm{H}_{2}$ : Locus of Control berpengaruh positif dan signifikan terhadap Kinerja Karyawan

\section{METODE PENELITIAN}

Penelitian merupakan penelitian bersifat asosiatif yang digunakan untuk menguji hubungan antara dua variabel atau lebih. Penelitian ini dilakukan pada karyawan perusahaan Ramayana Mal Bali yang terletak di Jalan Ponogoro Denpasar. Variabel terikat penelitian ini adalah kinerja karyawan(Y). Variabel bebas penelitian ini adalah self efficacy $\left(\mathrm{X}_{1}\right)$ dan locus of control $\left(\mathrm{X}_{2}\right)$.

Populasi pada penelitian ini adalah seluruh karyawan bagian penjualan Ramayana Mal Bali dengan jumlah 176 orang. Teknik pengambilan sampel yang 
dilakukan yaitu dengan menggunakan rumus slovin (Riduwan, 2007:65) yaitu:

$\mathrm{I}=\frac{\mathrm{N}}{\mathrm{N} \cdot \mathrm{d}^{+}+1}$

Keterangan:

n : Jumlah Sampel

$\mathrm{N}$ : Jumlah Populasi $=176$ responden

d : Presisi (ditetapkan 10 persen)

$\mathrm{II}=\frac{1 / 6}{1+176 \cdot(0 \cdot 10)^{2}}$

$\mathrm{n}=\frac{1 / 6}{2.16}$

$\mathrm{n}=63.7$ dibulatkan menjadi 64

Berdasarkan hasil perhitungan tersebut, jumlah sampel yang perlu diteliti minimal 64 orang. Metode yang digunakan dalam menentukan sampel penelitian menggunakan teknik simple random sampling. Metode pengumpulan data yang dipergunakan adalah observasi, wawancara dan kuesioner

Jenis data dalam penelitian ini meliputi data kualitatif, yaitu: hasil survei dan wawancara yang dilakukan dengan manajer sumber daya manusia perusahaan Ramayana Mal Bali. Data kuantitatif, yaitu: skor dari kuesioner yang telah diisi oleh karyawan, jumlah karyawan, masa kerja, usia karyawan serta data penjualan dari Ramayana Mal Bali. Sumber data dalam penelitian ini adalah sumber primer, yaitu: karyawan Ramayana Mal Bali yang menjadi narasumber langsung pada penelitian ini. Sumber sekunder, yaitu: data jumlah karyawan, penjualan, serta pengaduan konsumen terhadap layanan dari karyawan yang diperoleh dari manajer SDM Ramayana Mal Bali. 
Teknik analisis data dalam penelitian ini menggunakan metode regresi linier beranda untuk mengetahui pengaruh self efficacy $\left(\mathrm{X}_{1}\right)$, locus of $\operatorname{control}\left(\mathrm{X}_{2}\right)$ dan kinerja(Y). Metode ini diuji menggunakan sistem komputer berupa spss.21. Pengaruh variabel independen terhadap variabel dependen diuji dengan tingkat kepercayaan $95 \%$ atau $\alpha=5 \%$. Model regresi yang digunakan adalah sebagai berikut:

$\mathrm{Y}=\alpha+\beta_{1} \mathrm{X}_{1}+\beta_{2} \mathrm{X}_{2}+\varepsilon$

Keterangan:

$\mathrm{Y} \quad=$ Kinerja

$\mathrm{X}_{1} \quad=$ Self efficacy

$\mathrm{X}_{2} \quad=$ Locus of control

$\alpha \quad=$ Konstanta

$\beta_{1} \quad=$ Koefisien regresi self efficacy

$\beta_{2} \quad=$ Koefisien regresi locus of control

$\varepsilon \quad=$ eror

\section{HASIL DAN PEMBAHASAN}

Suatu instrumen dikatakan valid apabila koefisien korelasi antar butir pertanyaan $>0,361$.

Tabel 1.

Hasil Uji Validitas Instrumen Penelitian

\begin{tabular}{|c|c|c|c|c|c|}
\hline \multirow[b]{2}{*}{ No. } & \multirow[b]{2}{*}{ Variabel } & \multirow[b]{2}{*}{ Item } & \multicolumn{2}{|c|}{ Validitas } & \multirow[b]{2}{*}{ Keterangan } \\
\hline & & & $\begin{array}{c}\text { Koefisien } \\
\text { Korelasi }\end{array}$ & Standar & \\
\hline \multirow[t]{3}{*}{1} & Self Efficacy $\left(\mathrm{X}_{1}\right)$ & $\mathrm{X} 1.1$ & 0,859 & 0,361 & Valid \\
\hline & & $\mathrm{X} 1.2$ & 0,649 & 0,361 & Valid \\
\hline & & $\mathrm{X} 1.3$ & 0,759 & 0,361 & Valid \\
\hline \multirow[t]{10}{*}{2} & Locus of Control (X2) & $\mathrm{X} 2.1$ & 0,718 & 0,361 & Valid \\
\hline & & $\mathrm{X} 2.2$ & 0,470 & 0,361 & Valid \\
\hline & & $\mathrm{X} 2.3$ & 0,562 & 0,361 & Valid \\
\hline & & $\mathrm{X} 2.4$ & 0,427 & 0,361 & Valid \\
\hline & & $\mathrm{X} 2.5$ & 0,407 & 0,361 & Valid \\
\hline & & $\mathrm{X} 2.6$ & 0,741 & 0,361 & Valid \\
\hline & & $\mathrm{X} 2.7$ & 0,631 & 0,361 & Valid \\
\hline & & $\mathrm{X} 2.8$ & 0,612 & 0,361 & Valid \\
\hline & & $\mathrm{X} 2.9$ & 0,773 & 0,361 & Valid \\
\hline & & $\mathrm{X} 2.10$ & 0,391 & 0,361 & Valid \\
\hline
\end{tabular}

Sumber: Data primer diolah, 2017 
Semua variabel memiliki nilai koefisien korelasi berada di atas 0,361 , sehingga seluruh item di tiap variabel tersebut layak dijadikan instrumen penelitian.

Tabel 2.

Hasil Uji Reliabilitas

\begin{tabular}{|c|c|c|c|c|c|}
\hline \multirow[b]{2}{*}{ No. } & \multirow[b]{2}{*}{ Variabel } & \multirow[b]{2}{*}{ Item } & \multicolumn{2}{|c|}{ Reliabilitas } & \multirow[b]{2}{*}{ Keterangan } \\
\hline & & & $\begin{array}{c}\text { Alpha } \\
\text { Cronbach }\end{array}$ & Standar & \\
\hline 1 & Self Efficacy & $\mathrm{X}_{1}$ & 0,632 & 0,6 & Reliabel \\
\hline 2 & Locus of Control & $X_{2}$ & 0,772 & 0,6 & Reliabel \\
\hline 3 & Kinerja karyawan & Y & 0,631 & 0,6 & Reliabel \\
\hline
\end{tabular}

Suatu instrumen dikatakan reliabel bila nilai Cronbach's Alpha $\geq 0,60$.

Berdasarkan Tabel 2 tersebut, semua variabel memiliki nilai koefisien Cronbach Alpha berada di atas 0,6 sehingga semua instrumen tersebut adalah reliabel, sehingga layak dijadikan instrumen penelitian.

Karakteristik responden penelitian ini merupakan profil dari 64 responden yang berpartisipasi dalam pengisian kuesioner. Data karakteristik responden pada Tabel 3 meliputi usia, jenis kelamin, pendidikan terakhir, dan masa kerja yang diuraikan sebagai berikut: 1) Usia digunakan untuk mengetahui usia dari para responden pada penelitian ini. Jumlah responden yang telah berusia kurang dari 21 tahun berjumlah 20 orang, berusia 21-30 tahun berjumlah 40 orang, berusia3140 tahun berjumlah 3 orang, dan berusia 41-50 tahun berjumlah berjumlah 1 orang. 2) Jenis Kelamin digunakan untuk mengetahui jenis kelamin dari para responden pada penelitian ini. Semua responden adalah perempuan hal ini dikarenakan kebijakan yang di terapkan oleh pihak Ramayana untuk memenuhi spesifikasi pekerjaan tersebut. 3) Pendidikan terakhir digunakan untuk 
mengetahui tingkat pendidikan dari para responden pada penelitian ini. Jumlah responden yang telah menempuh pendidikan terakhir SMA berjumlah 45 orang, SMK berjumlah 18 orang, dan sarjana berjumlah 1 orang. 4) Karakteristik responden berdasarkan lama bekerja sebagai karyawan dapat menjelaskan pengalaman kerja responden. Dapat dilihat bahwa responden yang telah bekerja kurang dari 1 tahun sebanyak 11 orang, yang telah bekerja 1-5 tahun sebanyak 52 orang, dan yang telah bekerja selama lebih dari 10 tahun sebanyak 1 orang.

Tabel 3.

Karakteristik Responden

\begin{tabular}{|c|c|c|c|}
\hline No & Variabel & Klasifikasi & Jumlah (Orang) \\
\hline \multirow[t]{5}{*}{1} & Usia & $<21$ tahun & 20 \\
\hline & & 21-30 tahun & 40 \\
\hline & & $31-40$ tahun & 3 \\
\hline & & $41-50$ tahun & 1 \\
\hline & Jumlah & & 64 \\
\hline \multirow[t]{3}{*}{2} & Jenis Kelamin & Laki-Laki & 0 \\
\hline & & Perempuan & 64 \\
\hline & Jumlah & & 64 \\
\hline \multirow[t]{4}{*}{3} & Pendidikan & SMA & 45 \\
\hline & & SMK & 18 \\
\hline & & Sarjana & 1 \\
\hline & Jumlah & & 64 \\
\hline \multirow[t]{4}{*}{4} & Masa Kerja & $<12$ bulan ( 1 tahun) & 11 \\
\hline & & $13-60$ bulan (1-5 tahun) & 52 \\
\hline & & $>120$ bulan (>10 tahun) & 1 \\
\hline & Jumlah & & 64 \\
\hline
\end{tabular}

Sumber: Data primer diolah, 2017

Deskripsi data akan diuraikan persepsi responden terhadap variabel Self Efficacy, Locus of Control, dan Kinerja karyawan yang diperoleh melalui penyebaran kuesioner. Penilaian secara kuantitatif menggunakan skala interval dengan mengintegrasikan rata-rata skor menurut kategori penilaiannya. Rumus (Usman dan Akbar, 2006:84) 
Nilai tertinggi $=5$

Nilai terendah $=1$

Rentang $\quad=5-1=4$

Kelas Interval $(\mathrm{p}) \quad=\frac{\text { Kentang }}{\text { Banyak Klas }}$

$$
\begin{aligned}
& =\frac{4}{2} \\
& =0,8
\end{aligned}
$$

Interval klas 0,8 bisa ditentukan kriteria mengenai Locus of Control, untuk poin 6-10 penilaian responden di balik (Reverse) untuk menyesuaikan indikator yang favorabel dengan indikator yang unfavorabel dan untuk menghidari adanya bias dan jawaban mekanis (Arsham, 2015):

$$
\begin{array}{ll}
\text { Nilai } 1,00-1,80 & =\text { Sangat tinggi } \\
\text { Nilai } 1,81-2,60 & =\text { Tinggi } \\
\text { Nilai } 2,61-3,40 & =\text { Sedang } \\
\text { Nilai 3,41-4,20 } & =\text { Rendah } \\
\text { Nilai 4,21-5,00 } & =\text { Sangat rendah }
\end{array}
$$

Sedangkan Self Efficacy dan Kinerja karyawan adalah dengan kriteria sebagai berikut:

$\begin{array}{ll}\text { Nilai } 1,00-1,80 & =\text { Sangat rendah } \\ \text { Nilai } 1,81-2,60 & =\text { Rendah } \\ \text { Nilai 2,61-3,40 } & =\text { Sedang } \\ \text { Nilai 3,41-4,20 } & =\text { Tinggi } \\ \text { Nilai 4,21-5,00 } & =\text { Sangat tinggi }\end{array}$


Tabel 4.

Deskripsi Jawaban Responden Terhadap Variabel Self Efficacy

\begin{tabular}{|c|c|c|c|c|c|c|c|c|c|}
\hline \multirow{3}{*}{ No } & \multirow{3}{*}{ Indikator } & \multicolumn{5}{|c|}{ Skor Jawaban } & \multirow{3}{*}{$\begin{array}{l}\text { Jum- } \\
\text { lah } \\
\text { skor }\end{array}$} & \multirow{3}{*}{$\begin{array}{l}\text { Rata- } \\
\text { rata } \\
\text { skor }\end{array}$} & \multirow{3}{*}{$\begin{array}{c}\text { Keteran } \\
\text { gan }\end{array}$} \\
\hline & & STS & TS & $\mathbf{R R}$ & $\mathbf{S}$ & SS & & & \\
\hline & & 1 & 2 & 3 & 4 & 5 & & & \\
\hline 1 & $\begin{array}{l}\text { Yakin dengan kemampuan } \\
\text { yang dimiliki dalam } \\
\text { menyelesaikan tugas. }\end{array}$ & 0 & 6 & 10 & 40 & 8 & 242 & 3.78 & Tinggi \\
\hline 2 & $\begin{array}{l}\text { Mampu menyelesaikan tugas } \\
\text { yang lebih sulit dari biasanya } \\
\text { dalam pekerjaan. }\end{array}$ & 0 & 9 & 26 & 29 & 0 & 212 & 3.31 & Sedang \\
\hline 3 & $\begin{array}{l}\text { Mampu menyelesaikan tugas } \\
\text { yang diberikan dalam berbagai } \\
\text { aktivitas. }\end{array}$ & 0 & 7 & 19 & 35 & 3 & 226 & 3.53 & Tinggi \\
\hline \multicolumn{7}{|c|}{ Rata-rata skor $S$} & & 3,54 & \\
\hline
\end{tabular}

Sumber: Data primer diolah, 2017

Berdasarkan Tabel 4 terlihat bahwa rata-rata skor tertinggi berada dipernyataan X1.1 dengan rata-rata 3,78 pernyataan ini masuk dalam kategori tinggi karena berada dalam interval 3,41-4,20. Rata-rata skor terendah berada dipernyataan X1.2 dengan rata-rata 3,31 pernyataan ini masuk dalam kategori sedang karena berada dalam interval 2,61-3,40. Secara keseluruhan variabel Self Efficacy dalam kategori tinggi karena memiliki rata-rata skor sebesar 3,54 yang berada di kisaran 3,41-4,20. Hal ini berarti bahwa Self Efficacy pada Karyawan Ramayana Mal Bali berada pada posisi yang tinggi.

Berdasarkan Tabel 5. terlihat bahwa rata-rata skor tertinggi berada dipernyataan X2.1 dengan rata-rata 4,53 pernyataan ini masuk dalam kategori sangat tinggi karena berada dalam interval 4,21-5,00. Rata-rata skor terendah berada dipernyataan X2.6 dengan rata-rata 4,13 pernyataan ini masuk dalam karegori rendah karena berada dalam inteval 3,41-4,20 (R). Secara keseluruhan variabel Locus of Control masuk dalam kategori tinggi karena memiliki rata-rata skor sebesar 3,97 yang berada di kisaran 3,41-4,20. Hal ini berarti bahwa Locus of Control pada Karyawan Ramayana Mal Bali berada pada posisi yang tinggi. 
Tabel 5.

Deskripsi Jawaban Responden Terhadap Variabel Locus of Control

\begin{tabular}{|c|c|c|c|c|c|c|c|c|c|}
\hline \multirow{3}{*}{ No } & \multirow{3}{*}{ Indikator } & \multicolumn{5}{|c|}{ Skor Jawaban } & \multirow{3}{*}{$\begin{array}{l}\text { Jum- } \\
\text { lah } \\
\text { skor }\end{array}$} & \multirow{3}{*}{$\begin{array}{l}\text { Rata- } \\
\text { rata } \\
\text { skor }\end{array}$} & \multirow{3}{*}{$\begin{array}{c}\text { Keteran } \\
\text { gan }\end{array}$} \\
\hline & & STS & TS & $\mathbf{R R}$ & $\mathbf{S}$ & SS & & & \\
\hline & & 1 & 2 & 3 & 4 & 5 & & & \\
\hline 1 & $\begin{array}{l}\text { Selalu bersungguh-sungguh } \\
\text { dalam melakukan pekerjaan. }\end{array}$ & 0 & 0 & 0 & 30 & 34 & 290 & 4.53 & $\begin{array}{c}\text { Sangat } \\
\text { tinggi }\end{array}$ \\
\hline 2 & $\begin{array}{l}\text { mengerjakan sesuatu tanpa } \\
\text { harus diberi tahu terlebih } \\
\text { dahulu. }\end{array}$ & 0 & 0 & 9 & 35 & 20 & 267 & 4.17 & Tinggi \\
\hline 3 & $\begin{array}{l}\text { Selalu berusaha untuk } \\
\text { memecahkan masalah yang } \\
\text { dihadapi dalam pekerjaan. }\end{array}$ & 0 & 1 & 1 & 50 & 12 & 265 & 4.14 & Tinggi \\
\hline 4 & $\begin{array}{l}\text { Memiliki anggapan bahwa } \\
\text { semua pekerjaan bisa } \\
\text { diselesaikan dengan benar. }\end{array}$ & 0 & 0 & 8 & 47 & 9 & 257 & 4.02 & Tinggi \\
\hline 5 & $\begin{array}{l}\text { Percayaan bahwa keberhasilan } \\
\text { diperoleh dari usaha yang } \\
\text { dilakukan. }\end{array}$ & 0 & 0 & 4 & 34 & 26 & 278 & 4.34 & $\begin{array}{l}\text { Sangat } \\
\text { tinggi }\end{array}$ \\
\hline 6 & $\begin{array}{l}\text { Mudah menyerah dalam } \\
\text { menyelesaikan suatu masalah } \\
\text { dalam pekerjaan. }\end{array}$ & 0 & 2 & 6 & 38 & 18 & 264 & 4.13 & Rendah \\
\hline 7 & $\begin{array}{l}\text { Keberhasilan yang diperoleh } \\
\text { sebagian besar merupakan } \\
\text { keberuntungan. }\end{array}$ & 0 & 5 & 35 & 19 & 5 & 216 & 3.38 & Sedang \\
\hline 8 & $\begin{array}{l}\text { Lebih senang mendapatkan } \\
\text { informasi dari rekan kerja } \\
\text { daripada harus mencari } \\
\text { informasi sendiri. }\end{array}$ & 0 & 2 & 12 & 42 & 8 & 248 & 3.88 & Rendah \\
\hline 9 & $\begin{array}{l}\text { Percaya usaha tidak } \\
\text { menentukan kesuksesan yang } \\
\text { dicapai. }\end{array}$ & 0 & 2 & 14 & 32 & 16 & 254 & 3.97 & Rendah \\
\hline 10 & $\begin{array}{l}\text { Selalu meminta pertimbangan } \\
\text { pada orang lain sebelum } \\
\text { bertindak. }\end{array}$ & 0 & 5 & 44 & 12 & 3 & 205 & 3.20 & Sedang \\
\hline \multicolumn{8}{|c|}{ Rata-rata skor Locus of Control } & 3.97 & \\
\hline
\end{tabular}

Sumber: Data primer diolah, 2017

Berdasarkan Tabel 6 terlihat bahwa rata-rata skor tertinggi berada di pernyataan Y1 dengan rata-rata 4,16 pernyatan ini masuk dalam kategori tinggi karena berada dalam interval 3,41-4,20. Rata-rata skor terendah berada pada pernyataan Y5 dengan rata-rata 3,28 pernyataan ini masuk dalam kategori sedang karena berada pada interval 2,61-3,40. 
Tabel 6.

Deskripsi Jawaban Responden Terhadap Variabel Kinerja Karyawan

\begin{tabular}{|c|c|c|c|c|c|c|c|c|c|}
\hline \multirow{3}{*}{ No } & \multirow{3}{*}{ Indikator } & \multicolumn{5}{|c|}{ Skor Jawaban } & \multirow{3}{*}{$\begin{array}{l}\text { Jum- } \\
\text { lah } \\
\text { skor }\end{array}$} & \multirow{3}{*}{$\begin{array}{l}\text { Rata- } \\
\text { rata } \\
\text { skor }\end{array}$} & \multirow{3}{*}{$\begin{array}{l}\text { Keteran } \\
\text { gan }\end{array}$} \\
\hline & & STS & TS & $\mathbf{R R}$ & $\mathbf{S}$ & SS & & & \\
\hline & & 1 & 2 & 3 & 4 & 5 & & & \\
\hline 1 & $\begin{array}{l}\text { Memberikan pelayanan yang } \\
\text { baik kepada pengunjung. }\end{array}$ & 0 & 2 & 9 & 30 & 23 & 266 & 4.16 & Tinggi \\
\hline 2 & $\begin{array}{l}\text { Mampu menghasilkan } \\
\text { penjualan sesuai target yang } \\
\text { ditentuka perusahaan. }\end{array}$ & 0 & 1 & 19 & 35 & 9 & 244 & 3.81 & Tinggi \\
\hline 3 & $\begin{array}{l}\text { Mampu mencapai target } \\
\text { penjualan sesuai dengan waktu } \\
\text { yang di tentukan perusahaan. }\end{array}$ & 0 & 4 & 22 & 33 & 5 & 231 & 3.61 & Tinggi \\
\hline 4 & $\begin{array}{l}\text { Mampu menyelesaikan } \\
\text { pekerjaan tanpa ada kesalahan. }\end{array}$ & 0 & 4 & 33 & 23 & 4 & 219 & 3.42 & Tinggi \\
\hline 5 & $\begin{array}{l}\text { Mampu menyelesaikan tugas } \\
\text { yang dibebankan tanpa bantuan } \\
\text { orang lain. }\end{array}$ & 0 & 10 & 30 & 20 & 4 & 210 & 3.28 & Sedang \\
\hline 6 & $\begin{array}{l}\text { Memiliki tanggung-jawab pada } \\
\text { perusahaan. }\end{array}$ & 0 & 4 & 7 & 29 & 24 & 265 & 4.14 & Tinggi \\
\hline \multicolumn{8}{|c|}{ Rata-rata skor Kinerja karyawan } & 3.73 & \\
\hline
\end{tabular}

Sumber: Data primer diolah, 2017

Secara keseluruhan variabel Kinerja masuk dalam kategori baik karena memiliki rata-rata skor 3,73 yang berada di kisaran 3,41-4,20. Hal ini berarti bahwa Kinerja karyawan Ramayana Mal Bali berada pada posisi tinggi.

Tabel 7.

Hasil Analisis Regresi Linier Berganda

\begin{tabular}{lcccccc}
\hline \multirow{1}{*}{\multicolumn{1}{c}{ Model }} & \multicolumn{2}{c}{$\begin{array}{c}\text { Unstandardized } \\
\text { Coefficients }\end{array}$} & \multicolumn{2}{c}{$\begin{array}{c}\text { Standardized } \\
\text { Coefficients }\end{array}$} & \multirow{2}{*}{ t } & \multirow{2}{*}{ Sig. } \\
\cline { 2 - 5 } & B & Std. Error & Beta & & \\
\hline (Constant) & -3.070 & 2.965 & & -1.035 & 0,305 \\
Self_efficacy & .976 & .167 & .540 & 5.842 & 0,000 \\
Locus_of_control & .382 & .094 & .374 & & 4.045 & 0,000 \\
\hline
\end{tabular}

Sumber: Data primer diolah, 2017

Persamaan regresi linear berganda pada penelitian ini berdasarkan Tabel 7 . sebagai berikut:

$$
\begin{aligned}
& Y=\alpha+\beta_{1} X_{1}+\beta_{2} X_{2}+\varepsilon \\
& Y=-3,070+0,976+0,382+\varepsilon
\end{aligned}
$$


Tabel 8.

Hasil Uji Normalitas

\begin{tabular}{cc}
\hline & Unstandardized Residual \\
\hline $\mathbf{N}$ & 64 \\
Kolmogorov-Smirnov $\boldsymbol{Z}$ & 0,678 \\
Asymp.Sig.(2-tailed) & 0,747 \\
\hline
\end{tabular}

Sumber:Data primer diolah, 2017

Nilai Kolmogorov-Smirnov sebesar 0,678 dan nilai Asymp. Sig. (2-tailed) sebesar 0,747 . Hal ini menunjukkan bahwa model persamaan regresi yang dibuat berdistribusi normal karena nilai Asymp. Sig. (2-tailed) 0,747 lebih besar dari nilai alpha 0,05 .

Tabel 9.

Hasil Uji Multikolinieritas

\begin{tabular}{ccc}
\hline Variabel & Tolerance & VIF \\
\hline Self Efficacy $\left(\mathrm{X}_{1}\right)$ & 0,594 & 1,684 \\
Locus of control $\left(\mathrm{X}_{2}\right)$ & 0,594 & 1,684 \\
\hline
\end{tabular}

Sumber:Data primer diolah, 2017

Nilai tolerance dan VIF dari variabel self efficacy dan locus of control, yang dimana nilai tolerance dari setiap variabel lebih besar dari 10 persen $(0,1)$ dan nilai VIF dari setiap variabel kurang dari 10. Hasil ini mengindikasikan tidak terdapat multikolineritas antara variabel self efficacy dan locus of control.

Tabel 10.

Hasil Uji Heteroskedastisitas

\begin{tabular}{|c|c|c|c|c|c|c|}
\hline \multirow[t]{2}{*}{ No } & \multirow[t]{2}{*}{ Model } & \multicolumn{2}{|c|}{$\begin{array}{l}\text { Unstandardized } \\
\text { coefficients }\end{array}$} & \multirow{2}{*}{$\begin{array}{c}\begin{array}{c}\text { Standardized } \\
\text { coefficients }\end{array} \\
\text { Beta } \\
\end{array}$} & \multirow[t]{2}{*}{$\mathbf{T}$} & \multirow[t]{2}{*}{ Sig. } \\
\hline & & B & Std. Error & & & \\
\hline \multirow{3}{*}{1} & Constant & 4,177 & 1,744 & & 2,395 & 0,020 \\
\hline & Self Efficacy & $-0,049$ & 0,098 & $-0,080$ & $-0,495$ & 0,622 \\
\hline & Locus of control & $-0,055$ & 0,055 & $-0,160$ & $-0,987$ & 0,328 \\
\hline
\end{tabular}
Sumber: Data primer diolah, 2017

Tidak ada pengaruh variabel bebas self efficacy dan locus of control terhadap absolute residual (abs_res), baik secara serempak maupun parsial karena nilai Sig. dari variabel self efficacy dan locus of control masing-masing yaitu 
0,622 dan 0,328 . Nilai tersebut lebih besar dari 0,05 ini berarti model regresi yang dibuat tidak mengandung gejala heterokedastisitas.

Tabel 11.

Hasil Uji F

\begin{tabular}{llccccc}
\hline & Model & Sum of Squares & Df & Mean Square & F & Sig. \\
\hline 1 & Regression & 492,475 & 2 & 246,237 & 67,864 & $0,000^{\mathrm{b}}$ \\
& Residual & 221,334 & 61 & 3,628 & & \\
& Total & 713,809 & 63 & & & \\
\hline
\end{tabular}

Sumber:Data primer diolah, 2017

Model regresi penelitian ini dikatakan layak atau variabel bebas mampu menjelaskan variabel terikat dilihat dari hasil uji $\mathrm{F}$ dengan nilai signifikan anova lebih kecil dari alpha yaitu 0,05 (anova $<\alpha=0,05$ ). Tabel 11 menunjukkan bahwa nilai Sig. sebesar 0,000 lebih kecil dari nilai $\alpha=0,05$ yang artinya model regresi linear berganda pada penelitian ini layak digunakan sebagai alat analisis untuk menguji variabel bebas terhadap variabel terikat.

Uji t digunakan untuk menguji pengaruh masing-masing variabel bebas yaitu self efficacy dan locus of control terhadap variabel terikat yaitu kinerja karyawan. Jika Sig. $\mathrm{t}<0,05$ maka $\mathrm{H}_{0}$ ditolak dan $\mathrm{H}_{1}$ diterima. Jika Sig. $\mathrm{t}>0,05$ maka $\mathrm{H}_{0}$ diterima dan $\mathrm{H}_{1}$ ditolak. Hasil analisis pengaruh self efficacy terhadap kinerja karyawan diperoleh nilai Sig. $\mathrm{t}$ sebesar 0,000 dengan nilai koefisien beta sebesar 5.842. Nilai Sig. t 0,000 $<0,05$ mengindikasikan bahwa $\mathrm{H}_{0}$ ditolak dan $\mathrm{H}_{1}$ diterima. Hasil ini berarti self efficacy berpengaruh positif terhadap kinerja karyawan. Nilai positif dari koefisien regresi variabel self efficacy mengindikasikan bahwa apabila self efficacy meningkat, maka kinerja karyawan juga meningkat dan memiliki pengaruh positif.

Hasil analisis pengaruh locus of control terhadap kinerja karyawan diperoleh nilai Sig. t sebesar 0,000 dengan nilai koefisien beta sebesar 4.045. Nilai 
Sig t 0,000 $<0,05$ mengindikasikan bahwa $\mathrm{H}_{0}$ ditolak dan $\mathrm{H}_{1}$ diterima. Hasil ini berarti locus of control berpengaruh positif terhadap kinerja karyawan. Nilai positif dari koefisien regresi variabel locus of control mengindikasikan bahwa apabila locus of control meningkat, maka kinerja karyawan juga meningkat dan memiliki pengaruh positif.

\section{SIMPULAN DAN SARAN}

Berdasarkan pembahasan hasil penelitian, dapat ditarik simpulan Self efficacy berpengaruh positif dan signifikan terhadap Kinerja karyawan Ramayana Mal Bali. Ini menunjukkan bahwa setiap adanya peningkatan self efficacy maka kinerja karyawan juga akan meningkat dan berpengaruh secara positif. Locus of control mempunyai pengaruh positif dan signifikan terhadap Kinerja Karyawan Ramayana Mal Bali. Ini menunjukkan bahwa setiap adanya peningkatan locus of control maka kinerja karyawan juga akan meningkat dan berpengaruh secara positif.

Saran dari penelitian ini yang berkaitan dengan self efficacy, locus of control, dan kinerja karyawan pada Ramayana Mal Bali adalah perusahaan diharapkan mampu memberikan dukungan pada karyawannya, berupa pelatihan atau pendampingan saat karyawan tersebut mengerjakan tugas yang lebih sulit sampai karyawan tersebut merasa mampu mengerjakan suatu tugas secara individu. Pihak perusahaan diharapkan mampu meningkatkan inisiatif dari setiap karyawan dengan meningkatkan pengawasan dan tingkat disiplin dari karywan sehingga menjadi sebuah kebiasaan. Serta perusahaan diharapkan mampu meningkatkan kemampuan dan keberanian dari karyawan dalam pengambilan 
keputusan dengan memberikan pelatihan dan bimbingan dari senior dan atasannya. Perusahaan juga diharapkan mampu meningkatkan kemandirian dan kemampuan karyawannya dengan pelatihan dan pendampingan dari senior dan atasannya. Saran bagi penelitian selanjutnya, agar menambahkan variabel lain dalam penelitian mengenai kinerja karyawan dan tidak sebatas variabel self efficacy dan locus of control saja. Penelitian selajutnya diharapkan menambahkan variabel kontrol seperti umur responden, pendidikan atau masa kerja pada penelitiannya. Penelitian selanjutnya juga diharapkan dapat mengambil sample penelitian diluar lingkungan perusahaan yang bergerak dalam bisnis ritel.

\section{REFERENSI}

Appiah, F. and H. Addai. (2014). An Investigation Into The Causal Relationship Between Employees Locus Of Control And Contextual Performance. Journal Of Business and Behavioral Sciences. 26(2): 94-118.

Al Azhar. (2013). Pengaruh Konflik Peran, Ketidakjelasan Peran, Kesan Ketidakpastian Lingkungan, Locus Of Control Dan Motivasi Kerja Terhadap Kinerja Auditor (Studi Empiris Pada Kantor Akuntan Publik Di Pekanbaru, Padang Dan Batam). Jurnal Ekonomi. 21(4): 1-15.

Arshanti, Tutuk Ari. (2009). Hubungan antara Penetapan Tujuan, Self efficacydan Kinerja. Jurnal Bisnis dan ekonomi (JBE). 16(2): 97-110.

Ayudiati, Soraya Eka. 2010. Analisis Pengaruh Locus Of Control Terhadap Kinerja Dengan Etika Kerja Islam Sebagai Variabel Moderating (Studi Pada Karyawan Tetap Bank Jateng Semarang). Skripsi. Universitas Diponegoro.

Arsham, Hossein. (2015). Questionnaire Design and Surveys Sampling. http://home.ubalt.edu/ntsbarsh/stat-data/Surveys.htm. (diunduh tanggal 28 Juli 2017).

Basak Rituparna and Anjali Ghosh. (2011). International Conference on Education and Educational Psychology School Environment and Locus of Control in Relation to Job Satisfaction among School Teachers - A Study from Indian Perspective. Procedia-Social and Behavioral Sciences. 29(2011): 1199-1208. 
Cherian. Jacob \& Jolly Jacob. (2013). Impact of Self Efficacy on Motivation and Performance of Employees. International Journal of Business and Management. 8(14): 80-88.

Dewi, Agustina Kartika. (2014), Pengaruh Locus Of Control dan Motivasi Belajar Terhadap Prestasi Belajar Akuntansi Siswa Kelas XI IPS SMA Negeri 2 Sleman Tahun Ajaran 2013/2014. Skripsi. Fakultas Ekonomi UNY.

D1, Wuryaningsih dan Rini Kuswanti. (2013). Analisis Pengaruh Locus of Control Pada Kinerja Karyawan. https://publikasiilmiah.ums.ac.id (diunduh tanggal 11 Oktober 2016).

Engko, Cicilia. (2008). Pengaruh Kepuasan Kerja terhadap Kinerja Individual dengan Self Esteem dan Self efficacy sebagai Variabel Intervening. Jurnal Bisnis dan Akuntansi. 10(1): 1-12.

Elena, Milka, Escalera-Chavez, Carlos, Rojas-Kramer, Arturo COrdova-Rangel, Elena Moreno-Garcia, and Arturo Garcia-Santillan. (2015). Empirical Evidence on Locus of Control among Owner and Manager and Its Relation to Success Firms. Journal of Emerging Trends in Economics and Management Sciences (JETEMS). 6(3): 177-184.

Fadzilah, Ari. (2006). Analisis Pengaruh Pemberdayaan Karyawan dan Self Of Efficacy Terhadap Kinerja Karyawan Bagian Penjualan (Studi Kasus Pada Pt. Sinar Sosro Wilayah Pemasaran Semarang). Jurnal Studi Manajemen dan Organisasi. 3(1): 12-27.

Gurendrawati, Etty. Yunika Murdayanti, and Anindya Gita Putri. (2014). The Impact of Information Technology, Management Accounting System Characteristics, and Locus of Control to the Managerial Performance in the Telecommunication Service Companies. Integrative Business \& Economics Research. 4(01): 357-366.

Handayani, W. (2008). Dampak Komitmen Organisasi, Self Efficacy Terhadap Konflik Peran dan Kinerja Karyawati Pt. Hm Sampoerna Tbk. Di Surabaya. Jurnal Riset Ekonomi dan Bisnis. 8(2): 70-78.

Indrawati, Yeti. (2014). Pengaruh Self Esteem, Self Efficacy Dan Kepuasan Kerja Terhadap Kinerja Karyawan (Studi Kasus Perawat RS Siloam Manado). Jurnal Riset Bisnis dan Manajemen. 2(4): 12-24.

Jackson, Susan E. Schuler, Randall S. dan Werner, Steve. (2011). Pengelolaan Sumber Daya Manusia. Buku 2 Edisi 10. Jakarta: Salemba Empat. 
Kaseger, Regina G. (2013). Pengembangan Karir Dan Self efficacy Terhadap Kinerja Karyawan Pada PT. Matahari Department Store Manado Town Square. Jurnal EMBA. 1(4): 906-916.

Kilapong, S. N. (2013). Kepemimpinan Transformasional, Self Efficacy, Self Esteem Pengaruhnya terhadap Kepuasan Kerja Karyawan PT. Tropica Cocoprima Manado. Jurnal Riset Ekonomi, Manajemen, Bisnis dan Akuntansi, 1(4): 141-150.

Lunnenburg. Fred C. (2011). Self Efficacy in The Workplace: Implications for Motivation and Performance. Journal of Management, Business, and Administration. 14(1): 1-6.

Malik, Muhamad Abdur Rahman, Arif N. Butt, Jin Nam Chom. (2015). Rewards and Employee Creative Performance: Moderating Effects Of Creative SelfEfficacy, Reward Importance, and Locus Of Control. Journal of Organizational Behaviour. Wiley Online Library.36: 59-74.

Medhayanti, Ni Putu, Ketut Alit Suardana. (2015). Pengaruh Partisipasi Anggaran Terhadap Kinerja Manajerial Dengan Self Efficacy, Desentralisasi, Dan Budaya Organisasi Sebagai Variabel Pemoderasi. Jurnal Akuntansi. Universitas Udayana. 11(1): 155-170.

Modise, Disebo and Patient Rambe. (2017). Internal and External Locus of Control of Engineering Workforce in a Power Distribution Untility: Impications for Job Performace. African Journal of Business and Ecnomic Research. 12 (2\&3): 113-147.

Pinasti, Woro. (2011). Pengaruh Self efficacy, Locus Of Control dan Faktor Demografis Terhadap Kematangan Karir Mahasiswa UIN Syarif Hidayatullah Jakarta. Skripsi. Fakultas Psikologi UIN.

Phopal, Lin Gresing. (2012). Manajemen Sumber Daya Manusia Untuk Bisnis. Jakarta: Prenada.

Robbins, Stephen P. dan Timothy A. Judge. (2008). Perilaku Organisasi, Jakarta: Salemba Empat.

Rimper, Rinna. R dan Lotje K. (2014). Pengaruh Perencanaan Karir dan Self efficacy Terhadap Kinerja Karyawan Pada PT. PLN (Persero) Area Manado. Jurnal Emba. 2(4): 413-423.

Rahayuningsih, Sri dan Askar Yunianto. (2016). Analisis Pengaruh Locus Of Control Dan Self Efficacy Terhadap Kinerja Dengan Etika Kerja Islam Sebagai Variabel Moderating (Study Empiris Pada Perawat Di Rumah Sakit Islam Sultan Agung Semarang). Jurnal Ventura. 7(1): 39-52. 
Ridhawati Rakhmi, Ibnu Hifzani. (2014). Pengaruh Partisipasi Anggaran Terhadap Kinerja Manajerial Dengan Locus Of Control Sebagai Variabel Moderating. Jurnal Ekonomi dan Bisnis. 7(2): 46-63.

Trilolita Putri Ardi, Venna, Endang Siti Astuti M dan Cahyo Widyo Sulistyo. (2017). Pengaruh Self Efficacy Terhadap Employee Engagement Dan Kinerja Karyawan (Studi Pada Karyawan Pt Telekomunikasi Indonesia Regional V Surabaya). Jurnal Administrasi Bisnis. 52(1): 163-172.

Usman, Husaini dan Setiadi Akbar. (2006).Pengantar Statistik. PT Bumi Aksara: Jakarta

Wahyuni. Endang S. Taufeni Taufik, dan Vincen Ratnawati (2016). Pengaruh Budaya Organisasi, Locus of Control, Stres Kerja Terhadap Kinerja Aparat Pemerintah Daerah Dan Kepuasan Kerja Sebagai Variabel Intervening (Studi Empiris Pada Pemerintah Kabupaten Bengkalis). Jurnal Manajemen. 20(02): 189-206.

Widyaninggrat, Anggi Ajeng. (2014). Pengaruh Efikasi Diri dan Lokus Kendali (Locus Of Control) Terhadap Prestasi Belajar Matematika. Jurnal Formatif. Universitas Indraprasta PGRI. 4(2): 89-99.

Wirawan. (2009). Evaluasi Kinerja Sumber Daya Manusia. Jakarta: Salemba Empat.

Yi Li, Feng Wei, Shenggang Ren, Yang Di. (2014). Locus of Control, Psychological Empowerment and Intrinsic Motivation Relation to Performance. Jounal of Managerial Psychology. 30(4): 422-438. 